\title{
Efficient Inverted ITO-Free Organic Solar Cells Based on Transparent Silver Electrode with Aqueous Solution-Processed ZnO Interlayer
}

\author{
Zhizhe Wang, ${ }^{1,2}$ Dazheng Chen, ${ }^{2}$ Chunfu Zhang, ${ }^{2}$ Zhenhua Lin, ${ }^{2}$ Yan Liu, ${ }^{1}$ Genquan Han, \\ Jingjing Chang, ${ }^{2}$ Jincheng Zhang, ${ }^{2}$ Lixin Guo, ${ }^{3}$ and Yue $\mathrm{Hao}^{2}$ \\ ${ }^{1}$ China Electronic Product Reliability and Environmental Testing Research Institute, No. 110 Dongguanzhuang Road, Guangzhou \\ 510610, China \\ ${ }^{2}$ State Key Discipline Laboratory of Wide Band Gap Semiconductor Technology, School of Microelectronics, Xidian University, \\ 2 South Taibai Road, Xi'an 710071, China \\ ${ }^{3}$ School of Physics and Optoeletronic Engineering, Xidian University, 2 South Taibai Road, Xi'an 710071, China
}

Correspondence should be addressed to Dazheng Chen; dzchen@xidian.edu.cn and Chunfu Zhang; cfzhang@xidian.edu.cn

Received 21 January 2017; Accepted 9 May 2017; Published 18 June 2017

Academic Editor: Jegadesan Subbiah

Copyright (c) 2017 Zhizhe Wang et al. This is an open access article distributed under the Creative Commons Attribution License, which permits unrestricted use, distribution, and reproduction in any medium, provided the original work is properly cited.

\begin{abstract}
Efficient inverted organic solar cells (OSCs) with the $\mathrm{MoO}_{3}(2 \mathrm{~nm}) / \mathrm{Ag}(12 \mathrm{~nm})$ transparent cathode and an aqueous solution $\mathrm{ZnO}$ electron extraction layer processed at low temperature are investigated in this work. The blend of low bandgap poly[[ 4,8 -bis[ $(2-$ ethylhexyl)oxy]benzo[1,2-b:4,5-b']dithiophene-2,6-diyl][3-fluoro-2-[(2-ethylhexyl)carbonyl]thieno[3,4-b]thiophenediyl]] (PTB7) and $[6,6]$-phenyl- $\mathrm{C}_{71}$-butyric acid methylester $\left(\mathrm{PC}_{71} \mathrm{BM}\right)$ is employed as the photoactive layer here. A power conversion efficiency (PCE) of 5.55\% is achieved for such indium tin oxide- (ITO-) free OSCs under AM 1.5G simulated illumination, comparable to that of ITO-based reference OSCs (PCE of 6.11\%). It is found that this ZnO interlayer not only slightly enhances the transparency of $\mathrm{MoO}_{3} / \mathrm{Ag}$ cathode but also obtains a lower root-mean-square (RMS) roughness on the $\mathrm{MoO}_{3} / \mathrm{Ag}$ surface. Meanwhile, ITO-free OSCs also show a good stability. The PCE of the devices still remains above $85 \%$ of the original values after 30 days, which is slightly superior to ITO-based reference OSCs where the $16 \%$ degradation in PCE is observed after 30 days. It may be instructive for further research of OSCs based on metal thin film electrodes.
\end{abstract}

\section{Introduction}

With the advantages of low cost, solution process, flexibility, and the potential of roll-to-roll mass fabrication, organic solar cells (OSCs) have attracted much more attention as one kind of the third generation solar cells [1-5]. In the past two decades, with the rapid development of the research, considerable improvement has been achieved in the photovoltaic performance of OSCs, particularly in the power conversion efficiency (PCE) and stability. Recently, it has been reported that the PCE of single junction and tandem organic solar cells [6-8] have already exceeded $10 \%$, which is regarded to be the limit for the large-scale commercialization of efficient OSCs [8-11].
Due to the high optical transparency in the visible light region and good conductivity, indium tin oxide (ITO) transparent electrode has found wide applications in light-emitting diodes and OSCs. However, the cheap and flexible electrode material is the prerequisite for rollto-roll mass production of OSCs, which ITO cannot meet. For instance, both the high-temperature process (usually sputter) and intrinsic brittleness of ITO make it a nonideal transparent electrode candidate for flexible devices [12]. What is more, indium is a scarce and toxic material, and thus, the highest share in material cost $[13,14]$ and energy input $[15,16]$ of ITO is inevitable in the fabrication of ITO-based OSCs. Therefore, more and more efforts are dedicated to the ITO-free or indium-free transparent 
electrodes, such as poly(3,4-ethylenedioxythiophene):poly(styrenesulfonate) (PEDOT:PSS) [17, 18], various transparent conducting oxides (Al-doped $\mathrm{ZnO}(\mathrm{AZO})$ or Ga-doped $\mathrm{ZnO}$ (GZO)) [19-21], Ag nanowires [22, 23], carbon nanotubes [24], graphene [25], and so on. However, although the PEDOT:PSS electrode can be prepared by simple solution process, its conductivity needs to be further improved $[26,27]$. Although the cost of AZO or GZO is lower than ITO, their similar brittleness and high-temperature sputter process are also undesirable. Meanwhile, the relatively large surface roughness of $\mathrm{Ag}$ nanowire, graphene, and carbon nanotube electrodes limits the carrier transport in devices [22, 24, 28]. Additionally, the complex preparation of these film electrodes is unsuitable for large-scale fabrication of OSCs. On the contrary, a metal thin film (for example Ag) can be easily fabricated by thermal evaporation. Moreover, due to their low absorption in the visible spectrum, high conductivity, smooth surface, and ductile nature, metal thin film electrodes are promising to be used for roll-to-roll mass production of OSCs [28]. Thus, more and more works are devoted to the research interest of transparent metal electrodes [28-31].

It has been reported in our previous works that the introduction of $2 \mathrm{~nm}$ thick unclosed $\mathrm{MoO}_{3}$ layer may create preferred nucleation sites on the substrate to enhance the lateral growth of Ag film, which improves the electrical, opti$\mathrm{cal}$, and morphological properties of $\mathrm{MoO}_{3} / \mathrm{Ag}$ electrodes [32-34]. Based on the optimal $\mathrm{MoO}_{3}(2 \mathrm{~nm}) / \mathrm{Ag}(9 \mathrm{~nm})$ anode with high transparency and good conductivity, ITOfree OSCs with a conventional structure are fabricated on glass substrates, and the resulted device shows the comparable performance compared to the ITO-based reference OSCs $[32,33]$. Furthermore, flexible ITO-free OSCs fabricated on poly(ethylene terephthalate) (PET) substrates exhibit a good performance and excellent mechanical flexibility [34], which reveals the potential of $\mathrm{Ag}$ electrode for the roll-to-roll mass fabrication of OSCs.

However, the conventional OSCs in above works show the fast performance degradation and the relatively poor stability even stored in the $\mathrm{N}_{2}$-filled glove box [33]. Fortunately, compared to conventional OSCs, the stability could be obviously improved by employing an inverted structure and more stable high work function metal anodes $[35,36]$. To develop ITO-free OSCs with high efficiency and better stability, inverted ITO-free OSCs are fabricated on the $\mathrm{MoO}_{3}(2 \mathrm{~nm}) / \mathrm{Ag}(12 \mathrm{~nm})$ electrode with an aqueousprocessed $\mathrm{ZnO}$ electron extraction layer. The blend of low bandgap poly[[4,8-bis[(2-ethylhexyl)oxy]benzo[1,2b:4,5-b'] dithiophene-2,6-diyl] [3-fluoro-2-[(2-ethylhexyl)carbonyl]thieno[3,4-b]thiophenediyl]] (PTB7) and [6,6]phenyl- $\mathrm{C}_{71}$-butyricacidmethylester $\left(\mathrm{PC}_{71} \mathrm{BM}\right)$ is used as the photoactive layer. By choosing a thicker Ag electrode to completely cover the underlying $\mathrm{MoO}_{3}$ layer, the erosion of $\mathrm{ZnO}$ solution to $\mathrm{MoO}_{3}$ is effectively prevented. The resulted ITO-free OSCs with an inverted structure obtains a PCE as high as 5.55\% under AM 1.5G simulated illumination, which is comparable to the PCE (6.11\%) of ITO-based reference OSCs. Moreover, these unencapsulated OSCs also show a good stability. Their PCE still remains above $85 \%$ of the original values after 30 days, which is slightly superior to ITO-based reference OSCs where the 16\% degradation in PCE is observed after 30 days. This further confirms the potential of our electrode for the future commercialization of OSCs. It is also instructive for further research of metal thin film electrodes.

\section{Experimental}

The inverted OSCs based on solution-processed $\mathrm{ZnO}$ interlayer and $\mathrm{MoO}_{3} / \mathrm{Ag}$ cathode were fabricated as following. Firstly, the $\mathrm{ZnO}$ pecursor of $0.125 \mathrm{M}\left(\mathrm{Zn}\left(\mathrm{NH}_{3}\right)_{4}^{2+}\right)$ solution was obtained by dissolving $\mathrm{ZnO}$ powder (particle size $<5 \mu \mathrm{m}$, Sigma-Aldrich) into ammonium hydroxide. The preparation details can be found in our previous work $[3,36]$. The blend of PTB7 (1 material) and PC $_{71}$ BM (American Dye Source) was dissolved in chlorobenzene containing 3\% 1,8-diiodooctane (Aldrich) and stirred at room temperature overnight. Then the PTB7:PC $\mathrm{P}_{71} \mathrm{BM}$ blend has a concentration of $25 \mathrm{mg} / \mathrm{mL}$ with a weight ratio of $1: 1.5$. Glass substrates were ultrasonically cleaned with detergent (Decon 90, UK), deionized water, acetone, ethanol, and deionized water for about $15 \mathrm{~min}$. All the materials were used without any further purification.

Secondly, the dried glass substrates were transferred into an ultrahigh vacuum chamber with a pressure below $5 \times 10^{-4} \mathrm{~Pa}$. To obtain the $\mathrm{MoO}_{3} / \mathrm{Ag}$ electrodes, $\mathrm{MoO}_{3}$ and Ag films were thermally evaporated on glass substrates sequentially with the evaporation rate of $0.02 \mathrm{~nm} / \mathrm{s}$ and $0.1 \mathrm{~nm} / \mathrm{s}$, and the details of electrode deposition can be found in our previous works [32-34]. The thickness of $2 \mathrm{~nm}$ given here has to be a nominal value obtained by the quartz crystal monitor calibrated with a step profiler, representing the amount of $\mathrm{MoO}_{3}$ on the sample. The optical transmittance and surface morphology of $\mathrm{MoO}_{3} / \mathrm{Ag}$ electrode were characterized by using an UV-vis spectrophotometer (Lambda 950, Perkin Elmer) from $200 \mathrm{~nm}$ to $1000 \mathrm{~nm}$ and the tapping mode atomic force microscopy (AFM, Agilent 5500).

Thirdly, after the electrode deposition, the device fabrication began with the deposition of $\mathrm{ZnO}$ cathode buffer layer. The $\mathrm{ZnO}$ aqueous precursor solution was spin-coated onto the $\mathrm{MoO}_{3} / \mathrm{Ag}$ surface at $3000 \mathrm{rpm}$ for $40 \mathrm{~s}$ and annealed in the oven at $150^{\circ} \mathrm{C}$ for $30 \mathrm{~min}$ in air. Then PTB7:PC ${ }_{71} \mathrm{BM}$ solution was spin-coated onto the $\mathrm{ZnO}$ surface at $1200 \mathrm{rpm}$ for $55 \mathrm{~s}$ in a $\mathrm{N}_{2}$-fulfilled glove box. Next, the samples were transferred into the vacuum chamber again, a $10 \mathrm{~nm}$ thick $\mathrm{MoO}_{3}$ layer and a $70 \mathrm{~nm}$ thick Ag layer were further evaporated upon the $\mathrm{PTB} 7: \mathrm{PC}_{71} \mathrm{BM}$ through a shadow mask to form the device anode. There are eight devices in one substrate, and each device has an active area of $12.5 \mathrm{~mm}^{2}$. Meanwhile, ITO-based OSCs were fabricated as the reference devices in the same process conditions. The geometry structure of fabricated devices based on the ITO and $\mathrm{MoO}_{3} / \mathrm{Ag}$ electrodes is illustrated in Figure 1. The current densityvoltage $(J-V)$ characteristics of unencapsulated devices were measured in air under the AM 1.5G solar simulator (1 sun, San-Ei Electric) with a Keithley 2400 source unit. The devices were illuminated from the substrates side, and the illumination intensity was kept at $1000 \mathrm{~W} / \mathrm{m}^{2}$ by using a silicon 


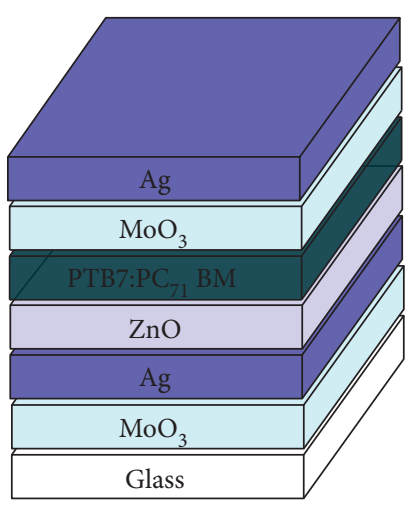

(a)

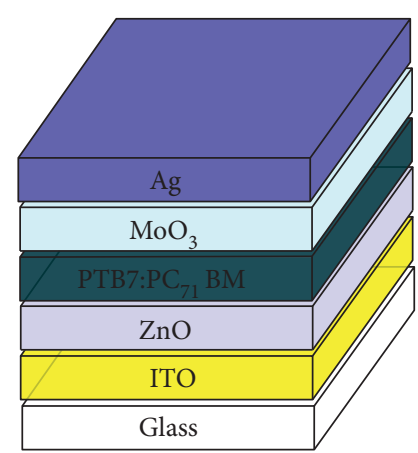

(b)

FIgURE 1: Schematic diagrams of inverted OSCs based on (a) the $\mathrm{MoO}_{3} / \mathrm{Ag}$ electrode and (b) the ITO electrode.

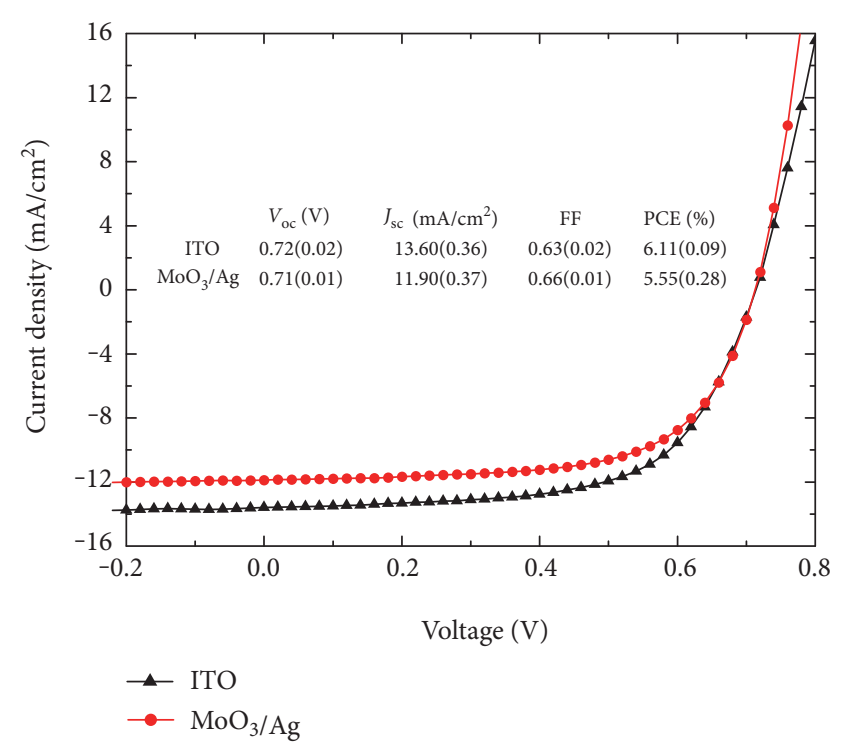

FIGURE 2: $J-V$ characteristics for inverted ITO-free OSCs based on $\mathrm{MoO}_{3} / \mathrm{Ag}$ electrode and ITO-based reference OSCs. The corresponding photovoltaic parameters have also been shown here as an inset for comparison.

standard solar cell which has been calibrated by the National Renewable Energy Laboratory. The stability of inverted ITOfree OSCs based on $\mathrm{MoO}_{3} / \mathrm{Ag}$ electrode and ITO-based reference OSCs is tested under ISOS-D-1, which is one of commonly used test protocols in dark for laboratory weathering testing under ambient conditions without light source and any loads [37]. The devices were stored in the $\mathrm{N}_{2}$-filled glove box $\left(\mathrm{H}_{2} \mathrm{O}, \mathrm{O}_{2}<10 \mathrm{ppm}\right)$ and measured under air ambient conditions.

\section{Results and Discussion}

The measured typical $J-V$ characteristics and corresponding photovoltaic parameters of ITO-free OSCs and ITO-based reference OSCs with an inverted structure are shown in Figure 2. Eight devices are measured for each kind of OSCs, and the values in the parentheses of Figure 2 represent

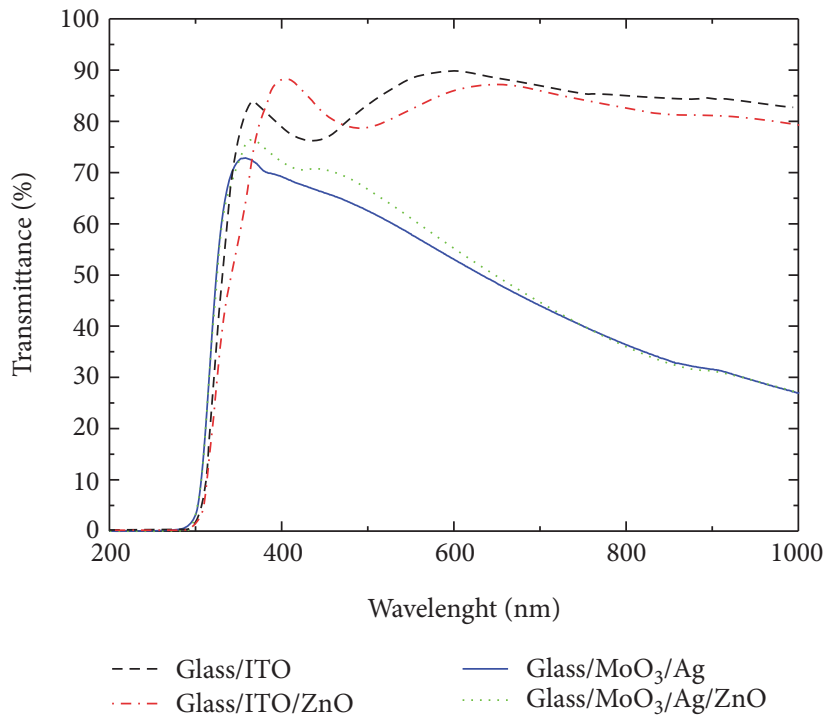

Figure 3: Optical transmittance of glass/ITO, glass $/ \mathrm{MoO}_{3} / \mathrm{Ag}$, glass/ITO/ZnO, and glass/ $\mathrm{MoO}_{3} / \mathrm{Ag} / \mathrm{ZnO}$ samples, respectively.

standard deviations of corresponding parameters. It can be seen that a PCE of $6.11 \%$ is achieved for ITO-based reference OSCs, with an open-circuit voltage $\left(V_{\mathrm{OC}}\right)$ of $0.72 \mathrm{~V}$, a shortcircuit current density $\left(J_{\mathrm{SC}}\right)$ of $13.60 \mathrm{~mA} \cdot \mathrm{cm}^{-2}$, and a fill factor (FF) of 63\%. Notably, the photovoltaic performance of ITOfree OSCs based on $\mathrm{MoO}_{3} / \mathrm{Ag}$ cathodes is comparable to that of ITO-based reference OSCs, with a comparable PCE of $5.55 \%$, a nearly identical $V_{\mathrm{OC}}$ of $0.71 \mathrm{~V}$, a slightly higher FF of $66 \%$, and a relatively smaller $J_{\mathrm{SC}}$ of $11.90 \mathrm{~mA} \cdot \mathrm{cm}^{-2}$. Here, the identical $V_{\text {OC }}$ for ITO-free devices demonstrates that the aqueous solution-processed $\mathrm{ZnO}$ interfacial modifying layer could efficiently block the hole and provide a suitable contact for electron extraction from PTB7: $\mathrm{PC}_{71} \mathrm{BM}$ to $\mathrm{MoO}_{3} / \mathrm{Ag}$ cathode.

To study the effect of different electrodes on the performance of OSCs, the wavelength-dependent transmittance spectra of glass/ITO and glass/ $\mathrm{MoO}_{3} / \mathrm{Ag}$ electrodes are characterized as well as that of glass/ITO/ZnO and glass $/ \mathrm{MoO}_{3} /$ $\mathrm{Ag} / \mathrm{ZnO}$ reference samples. As shown in Figure 3, a high transparency is achieved for the ITO electrode, with the first 


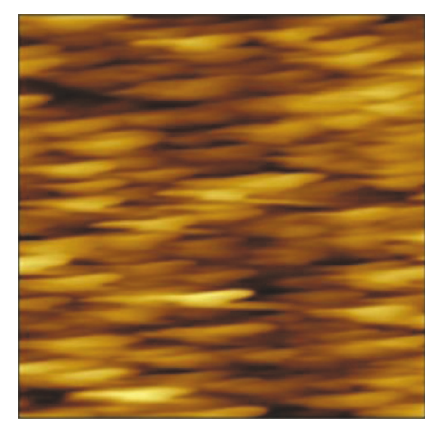

(a)

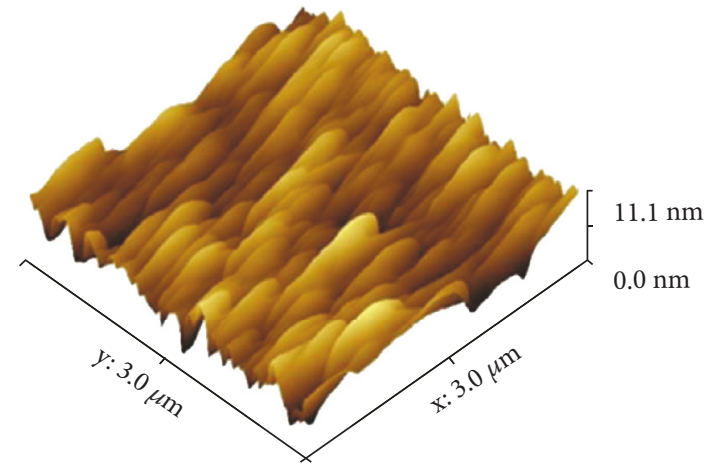

(c)

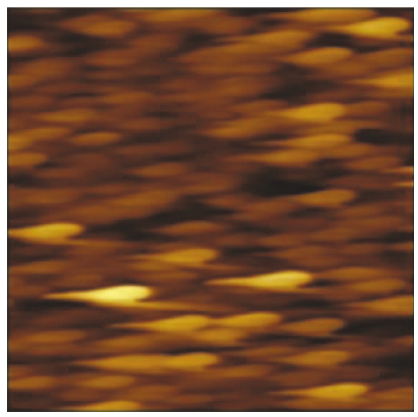

(b)

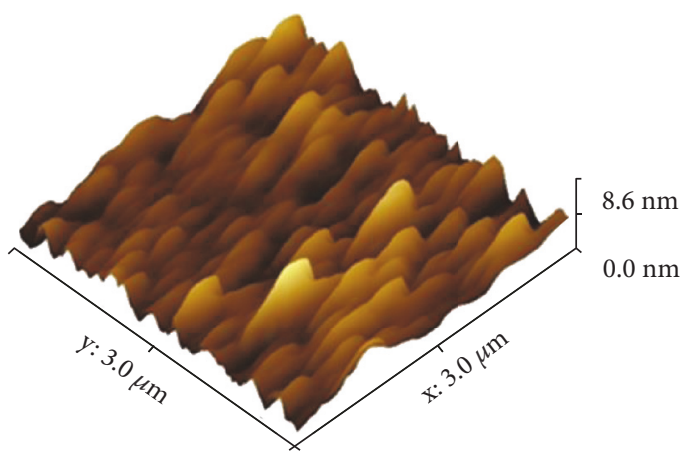

(d)

FIGURE 4: AFM images $(3 \mu \mathrm{m} \times 3 \mu \mathrm{m})$ of $\mathrm{ZnO}$ films fabricated on (a) the ITO and (b) the $\mathrm{MoO}_{3} / \mathrm{Ag}$ electrode. (c) and (d) are 3D plots for (a) and (b), respectively.

maximum of $84 \%$ at $367 \mathrm{~nm}$ and the second maximum of $90 \%$ at $600 \mathrm{~nm}$, respectively. Particularly, the average transparency of the electrode over $85 \%$ is achieved in the visible region. Compared with that of the ITO electrode, the transparency of the $\mathrm{MoO}_{3}(2 \mathrm{~nm}) / \mathrm{Ag}(12 \mathrm{~nm})$ electrode is relatively lower in the visible and near-infrared spectral range, with the maximum of $73 \%$ at $358 \mathrm{~nm}$. Thus, the lower transparency of $\mathrm{MoO}_{3}(2 \mathrm{~nm}) / \mathrm{Ag}(12 \mathrm{~nm})$ electrode leads to a relatively smaller $J_{\mathrm{SC}}$ of $11.9 \mathrm{~mA} \cdot \mathrm{cm}^{-2}$ than the $J_{\mathrm{SC}}$ $\left(13.6 \mathrm{~mA} \cdot \mathrm{cm}^{-2}\right)$ of ITO-based reference OSCs. When coated with the $\mathrm{ZnO}$ layer, the first transmittance maximum of $89 \%$ and the second maximum of $87 \%$ for the stack glass/ ITO/ZnO sample are shifted to $403 \mathrm{~nm}$ and $656 \mathrm{~nm}$, respectively. Meanwhile, the transparency of the stack glass/ITO/ $\mathrm{ZnO}$ has been decreased to some extent in the region over $472 \mathrm{~nm}$, compared with that of the ITO electrode. More interestingly, it can be observed from Figure 3 that the transparency of the stack has been enhanced when depositing a $\mathrm{ZnO}$ buffer layer onto the $\mathrm{MoO}_{3}(2 \mathrm{~nm}) / \mathrm{Ag}(12 \mathrm{~nm})$ electrode. Due to the optical interference effect, compared with that of the $\mathrm{MoO}_{3}(2 \mathrm{~nm}) / \mathrm{Ag}(12 \mathrm{~nm})$ electrode, the transparency of the glass $/ \mathrm{MoO}_{3} / \mathrm{Ag} / \mathrm{ZnO}$ in the wavelength range from $350 \mathrm{~nm}$ to $705 \mathrm{~nm}$ has been improved with a maximum of $77 \%$ at $369 \mathrm{~nm}$ while it has been slightly decreased in other regions. Similar results can also be found in our previous work [34]. Since the light harvesting of photoactive materials is most efficient in the visible light region, this provides us an optical strategy to further enhance the performance of our inverted ITO-free OSCs by improving the transparency of the $\mathrm{ZnO} / \mathrm{Ag} / \mathrm{MoO}_{3}$ electrode with the optimized $\mathrm{ZnO}$ buffer layer thickness. It will be discussed in our future work.

To investigate the influence of different electrodes on the surface morphology and film formation of the $\mathrm{ZnO}$ layer, AFM tests are carried out for the glass/ITO/ZnO and glass/ $\mathrm{MoO}_{3} / \mathrm{Ag} / \mathrm{ZnO}$ samples. Figure 4 shows the tapping mode AFM images of the $\mathrm{ZnO}$ layer on the ITO electrode and the $\mathrm{MoO}_{3} / \mathrm{Ag}$ electrode, respectively. The value of root-meansquare (RMS) surface roughness is $1.11 \mathrm{~nm}$ for the $\mathrm{ZnO}$ layer deposited on the $\mathrm{MoO}_{3} / \mathrm{Ag}$ electrode, lower than that of the $\mathrm{ZnO}$ layer fabricated on the ITO electrode (RMS of $1.71 \mathrm{~nm}$ ). And the top to valley values are $11.1 \mathrm{~nm}$ and $8.6 \mathrm{~nm}$ for the $\mathrm{ZnO}$ films on ITO and $\mathrm{MoO}_{3} / \mathrm{Ag}$ electrodes, respectively. Both of them indicate the formation of the smoother $\mathrm{ZnO}$ layer on the $\mathrm{MoO}_{3} / \mathrm{Ag}$ electrode. Commonly, a smoother $\mathrm{ZnO}$ layer will lead to a lower trap concentration at the interface between the $\mathrm{ZnO}$ buffer layer and active layer and, thus, the improved electron extraction efficiency at the cathode [38]. This maybe one reason that a smoother $\mathrm{ZnO}$ layer fabricated on the $\mathrm{MoO}_{3} / \mathrm{Ag}$ electrode can achieve a higher FF for corresponding inverted ITO-free OSCs, compared with that of ITO-based reference OSCs.

Besides, the stability of photovoltaic parameters has also been investigated for inverted ITO-free OSCs. The unencapsulated devices are stored in the $\mathrm{N}_{2}$-filled glove box and measured under air ambient conditions. The normalized $V_{\mathrm{OC}}$, $J_{\mathrm{SC}}, \mathrm{FF}$, and PCE as a function of the time are shown in Figure 5 as well as the results of ITO-based reference OSCs for comparison. As the time goes, it is clear that the $V_{\mathrm{OC}}$ 


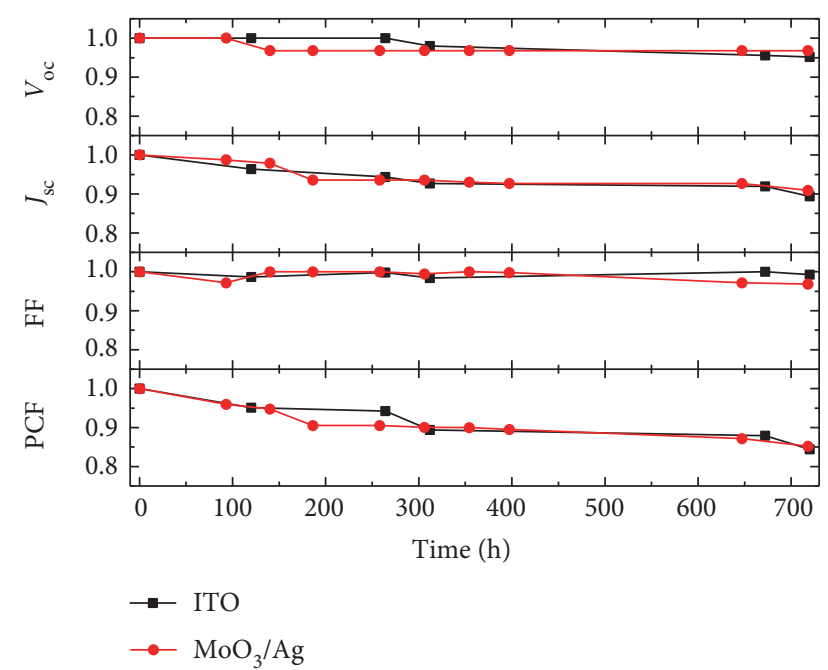

FIGURE 5: Variation of the normalized photovoltaic performance parameters with the time for ITO-free OSCs and ITO-based reference OSCs, respectively.

and FF for both devices decrease slightly, and the degradation in PCE is mainly attributed to the decrease in $J_{\mathrm{SC}}$. For ITObased reference OSCs, $V_{\mathrm{OC}}$ decreases by $5 \%$, FF decreases by $1 \%, J_{\mathrm{SC}}$ decreases by $11 \%$, and thus PCE decreases by $16 \%$ after 30 days. Meanwhile, for ITO-free OSCs, $V_{\mathrm{OC}}$ decreases by $3 \%$, FF decreases by $3 \%, J_{\text {SC }}$ decreases by $9 \%$, and thus PCE decreases by 15\% after 30 days. Obviously, our ITO-free OSCs show a good stability, slightly superior to ITO-based reference OSCs.

\section{Conclusion}

In this paper, based on the $\mathrm{MoO}_{3}(2 \mathrm{~nm}) / \mathrm{Ag}(12 \mathrm{~nm})$ cathode, efficient inverted ITO-free OSCs are fabricated with an aqueous solution-processed $\mathrm{ZnO}$ electron extraction layer. The blend of PTB7:PC ${ }_{71} \mathrm{BM}$ is employed as the photoactive layer here. A PCE of 5.55\% is achieved for such ITO-free OSCs under AM 1.5G simulated illumination, which is comparable to that of ITO-based reference OSCs (PCE of 6.11\%). Moreover, ITO-free OSCs also show a good stability. The PCE of the devices still remains above $85 \%$ of the original efficiency after 30 days, which is slightly superior to ITObased reference OSCs where the $16 \%$ degradation in PCE is observed after 30 days. It is instructive for further research of OSCs based on metal thin film electrodes.

\section{Conflicts of Interest}

The authors declare that they have no competing financial interests, and the mentioned received funding in Acknowledgments did not lead to any conflict of interests regarding the publication of this manuscript.

\section{Acknowledgments}

The work is partly financially supported by the National Natural Science Foundation of China (61334002, 61106063, and 61604199) and Class General Financial Grant from the China Postdoctoral Science Foundation (2016M602771).

\section{References}

[1] G. Yu, J. Gao, J. C. Hummelen, F. Wudl, and A. J. Heeger, "Polymer photovoltaic cells: enhanced efficiencies via a network of internal donor-acceptor heterojunctions," Science, vol. 270, no. 5243, pp. 1789-1791, 1995.

[2] L. Mohammad, A. F. Mitul, S. Sigdel et al., "Interface modification of inverted structure PSBTBT: $\mathrm{PC}_{70} \mathrm{BM}$ solar cells for improved performance," IEEE Journal of Photovoltaics, vol. 5, no. 6, pp. 1659-1664, 2015.

[3] C. Zhang, S. Pang, T. Heng et al., "Stable inverted low-bandgap polymer solar cells with aqueous solution processed lowtemperature $\mathrm{ZnO}$ buffer layers," International Journal of Photoenergy, vol. 2016, Article ID 3675036, 7 pages, 2016.

[4] F. C. Krebs, "Fabrication and processing of polymer solar cells: a review of printing and coating techniques," Solar Energy Materials and Solar Cells, vol. 93, no. 4, pp. 394-412, 2009.

[5] V. V. Travkin, A. Y. Luk'yanov, M. N. Drozdov, E. A. Vopilkin, P. A. Yunin, and G. L. Pakhomov, "Ultrathin metallic interlayers in vacuum deposited $\mathrm{MoOx} / \mathrm{metal} / \mathrm{MoOx}$ electrodes for organic solar cells," Applied Surface Science, vol. 390, pp. 703-709, 2016.

[6] M. A. Green, K. Emery, Y. Hishikawa, W. Warta, and E. D. Dunlop, "Solar cell efficiency tables (version49)," Progress in Photovoltaics, vol. 25, no. 1, pp. 3-13, 2017.

[7] J. Huang, C. Li, C. Chueh, S. Liu, J. Yu, and A. K. J. Jen, "10.4\% power conversion efficiency of ITO-free organic photovoltaics through enhanced light trapping configuration," Advanced Energy Materials, vol. 5, no. 15, article 1500406, 2015.

[8] J. You, L. Dou, K. Yoshimura et al., "A polymer tandem solar cell with $10.6 \%$ power conversion efficiency," Nature Communications, vol. 4, p. 1446, 2013.

[9] H. J. Son, B. Carsten, I. H. Jung, and L. Yu, "Overcoming efficiency challenges in organic solar cells: rational development of conjugated polymers," Energy \& Environmental Science, vol. 5, no. 8, pp. 8158-8170, 2012.

[10] Z. He, C. Zhong, S. Su, M. Xu, H. Wu, and Y. Cao, "Enhanced power-conversion efficiency in polymer solar cells using an inverted device structure," Nature Photonics, vol. 6, no. 9, pp. 591-595, 2012.

[11] T. D. Nielsen, C. Cruickshank, S. Foged, J. Thorsen, and F. C. Krebs, "Business, market and intellectual property analysis of polymer solar cells," Solar Energy Materials and Solar Cells, vol. 94, no. 10, pp. 1553-1571, 2010.

[12] J. Y. Lee, S. T. Connor, Y. Cui, and P. Peumans, "Solutionprocessed metal nanowire mesh transparent electrodes," Nano Letters, vol. 8, no. 2, pp. 689-692, 2008.

[13] A. L. Roes, E. A. Alsema, K. Blok, and M. K. Patel, "Ex-ante environmental and economic evaluation of polymer photovoltaics," Progress in Photovoltaics, vol. 17, no. 6, pp. 372-393, 2009.

[14] B. Azzopardi, C. J. M. Emmott, A. Urbina, F. C. Krebs, J. Mutale, and J. Nelson, "Economic assessment of solar electricity production from organic-based photovoltaic modules in a domestic environment," Energy \& Environmental Science, vol. 4, no. 10, pp. 3741-3753, 2011.

[15] N. Espinosa, R. García-Valverde, A. Urbina, and F. C. Krebs, "A lifecycle analysis of polymer solar cell modules prepared 
using roll-to-roll methods under ambient conditions," Solar Energy Materials and Solar Cells, vol. 95, no. 5, pp. 12931302, 2011.

[16] M. Kohlstädt, M. Grein, P. Reinecke, T. Kroyer, B. Zimmermann, and U. Würfel, "Inverted ITO-and PEDOT:PSS-free polymer solar cells with high power conversion efficiency," Solar Energy Materials and Solar Cells, vol. 117, pp. 98-102, 2013.

[17] Y. H. Kim, C. Sachse, M. L. Machala, C. May, L. MüllerMeskamp, and K. Leo, "Highly conductive PEDOT:PSS electrode with optimized solvent and thermal post-treatment for ITO-free organic solar cells," Advanced Functional Materials, vol. 21, no. 6, pp. 1076-1081, 2011.

[18] S. Choi, W. J. Potscavage, and B. Kippelen, "ITO-free largearea organic solar cells," Optics Express, vol. 18, no. 12, pp. A458-A466, 2010.

[19] H. Chen, A. D. Pasquier, G. Saraf, J. Zhong, and Y. Lu, "Dyesensitized solar cells using $\mathrm{ZnO}$ nanotips and $\mathrm{Ga}$-doped $\mathrm{ZnO}$ films," Semiconductor Science and Technology, vol. 23, no. 4, article 045004, 2008.

[20] H.-K. Park, J.-W. Kang, S.-I. Na, D.-Y. Kim, and H.-K. Kim, "Characteristics of indium-free GZO/Ag/GZO and AZO/Ag/ AZO multilayer electrode grown by dual target DC sputtering at room temperature for low-cost organic photovoltaics," Solar Energy Materials and Solar Cells, vol. 93, no. 11, pp. 19942002, 2009.

[21] N. Sun, G. Fang, P. Qin et al., "Bulk heterojunction solar cells with $\mathrm{NiO}$ hole transporting layer based on AZO anode," Solar Energy Materials and Solar Cells, vol. 94, no. 12, pp. 23282331, 2010.

[22] M. Raïssi, S. Vedraine, R. Garuz, T. Trigaud, and B. Ratier, "Solution processed cathode and interconnecting layer of silver nanowires in an efficient inverted tandem organic solar cells," Solar Energy Materials and Solar Cells, vol. 160, pp. 494-502, 2017.

[23] F. Guo, X. Zhu, K. Forberich et al., "ITO-free and fully solution-processed semitransparent organic solar cells with high fill factors," Advance Energy Materials, vol. 3, no. 8, pp. 1062-1067, 2013.

[24] J. Van De Lagemaat, T. M. Barnes, G. Rumbles et al., "Organic solar cells with carbon nanotubes replacing InO:Sn as the transparent electrode," Applied Physics Letters, vol. 88, no. 23 , article 233503, 2006.

[25] D. S. Hecht, L. Hu, and G. Irvin, "Emerging transparent electrodes based on thin films of carbon nanotubes, graphene, and metallic nanostructures," Advanced Materials, vol. 23, no. 13, pp. 1482-1513, 2011.

[26] D. Angmo and F. C. Krebs, "Flexible ITO-free polymer solar cells," Journal of Applied Polymer Science, vol. 129, no. 1, pp. 1-14, 2013.

[27] L. Cattin, J. C. Bernede, and M. Morsli, "Toward indium-free optoelectronic devices: dielectric/metal/dielectric alternative transparent conductive electrode in organic photovoltaic cells," Physica Status Solidi A-Applications and Materials Science, vol. 210, no. 6, pp. 1047-1061, 2013.

[28] W. Cao, Y. Zheng, Z. Li, E. Wrzesniewski, W. T. Hammond, and J. Xue, "Flexible organic solar cells using an oxide/metal/ oxide trilayer as transparent electrode," Organic Electronics, vol. 13, no. 11, pp. 2221-2228, 2012.

[29] S. D. Yambem, A. Haldar, K. S. Liao, E. P. Dillon, A. R. Barron, and S. A. Curran, "Optimization of organic solar cells with thin film Au as anode," Solar Energy Materials and Solar Cells, vol. 95, no. 8, pp. 2424-2430, 2011.

[30] S. Lim, D. Han, H. Kim, S. Lee, and S. Yoo, "Cu-based multilayer transparent electrodes: a low-cost alternative to ITO electrodes in organic solar cells," Solar Energy Materials and Solar Cells, vol. 101, pp. 170-175, 2012.

[31] D. Ghosh, R. Betancur, T. Chen, V. Pruneri, and J. Martorell, "Semi-transparent metal electrode of $\mathrm{Cu}-\mathrm{Ni}$ as a replacement of an ITO in organic photovoltaic cells," Solar Energy Materials and Solar Cells, vol. 95, no. 4, pp. 1228-1231, 2011.

[32] Z. Wang, C. Zhang, R. Gao et al., "Improvement of transparent silver thin film anodes for organic solar cells with a decreased percolation threshold of silver," Solar Energy Materials and Solar Cells, vol. 127, pp. 193-200, 2014.

[33] Z. Wang, C. Zhang, D. Chen et al., "ITO-free semitransparent organic solar cells based on silver thin film electrodes," International Journal of Photoenergy, vol. 2014, Article ID 209206, 7 pages, 2014.

[34] Z. Wang, C. Zhang, D. Chen et al., "Flexible ITO-free organic solar cells based on $\mathrm{MoO}_{3} / \mathrm{Ag}$ anodes," IEEE Photonics Journal, vol. 7, no. 1, pp. 1-9, 2015.

[35] S. K. Hau, H. L. Yip, N. S. Baek, J. Zou, K. O’Malley, and A. K. Y. Jen, "Air-stable inverted flexible polymer solar cells using zinc oxide nanoparticles as an electron selective layer," Applied Physics Letters, vol. 92, no. 25, article 253301, 2008.

[36] W. Wei, C. Zhang, D. Chen et al., "Efficient "light-soaking"free inverted organic solar cells with aqueous solution processed low-temperature $\mathrm{ZnO}$ electron extraction layers," ACS Applied Materials \& Interfaces, vol. 5, no. 24, pp. 1331813324, 2013.

[37] M. O. Reese, S. A. Gevorgyan, M. Jørgensen et al., “Consensus stability testing protocols for organic photovoltaic materials and devices," Solar Energy Materials and Solar Cells, vol. 95, pp. 1253-1267, 2011.

[38] Z. Ma, Z. Tang, E. Wang, M. R. Andersson, O. Inganäs, and F. Zhang, "Influences of surface roughness of $\mathrm{ZnO}$ electron transport layer on the photovoltaic performance of organic inverted solar cells," Journal of Physical Chemistry C, vol. 116, no. 46, pp. 24462-24468, 2012. 

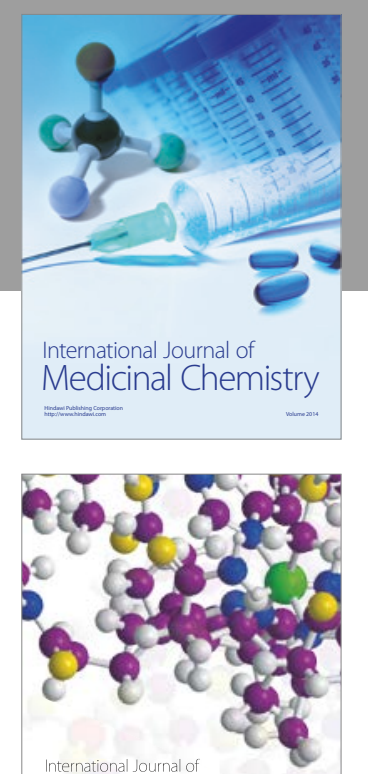

Carbohydrate Chemistry

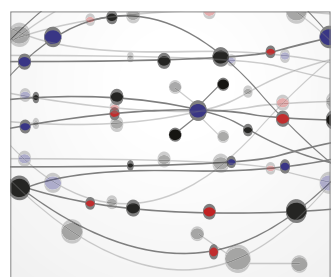

The Scientific World Journal
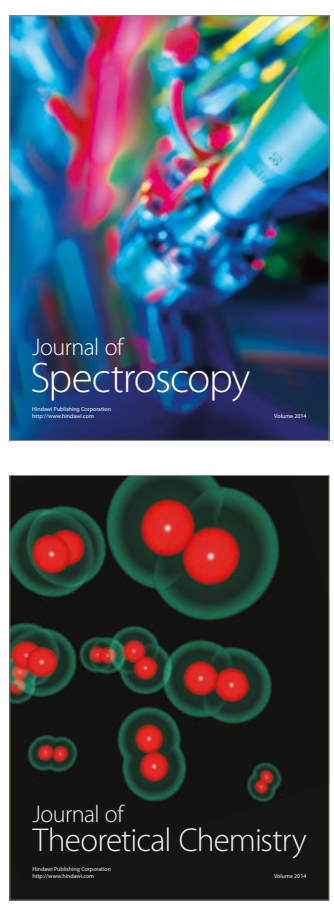
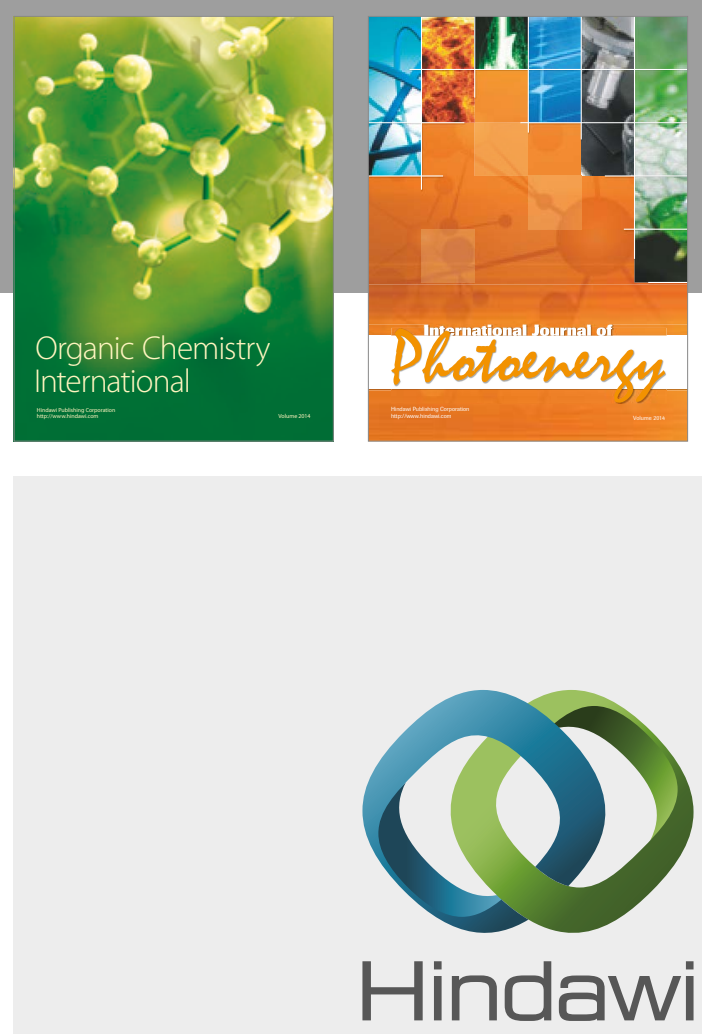

Submit your manuscripts at

https://www.hindawi.com

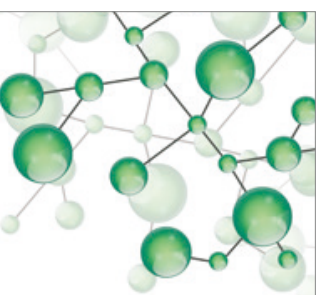

International Journal of

Inorganic Chemistry

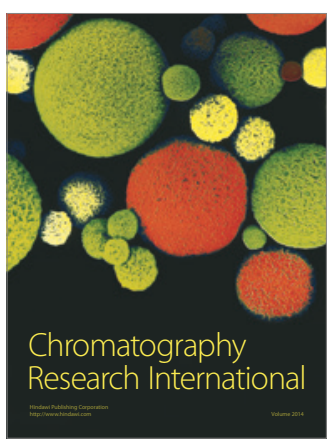

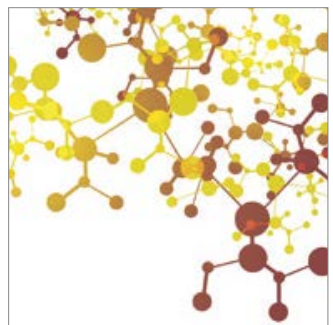

Applied Chemistry
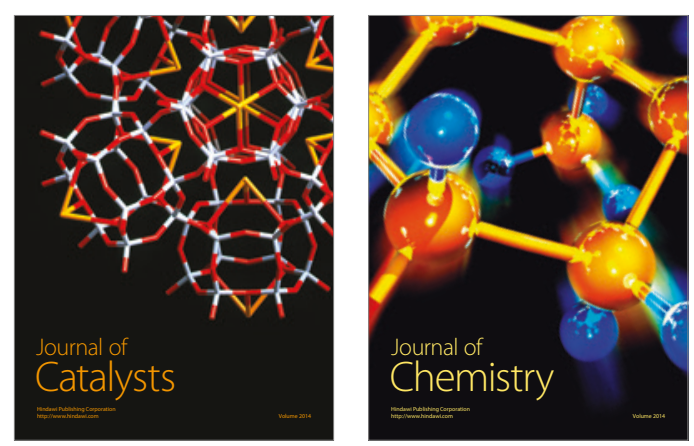
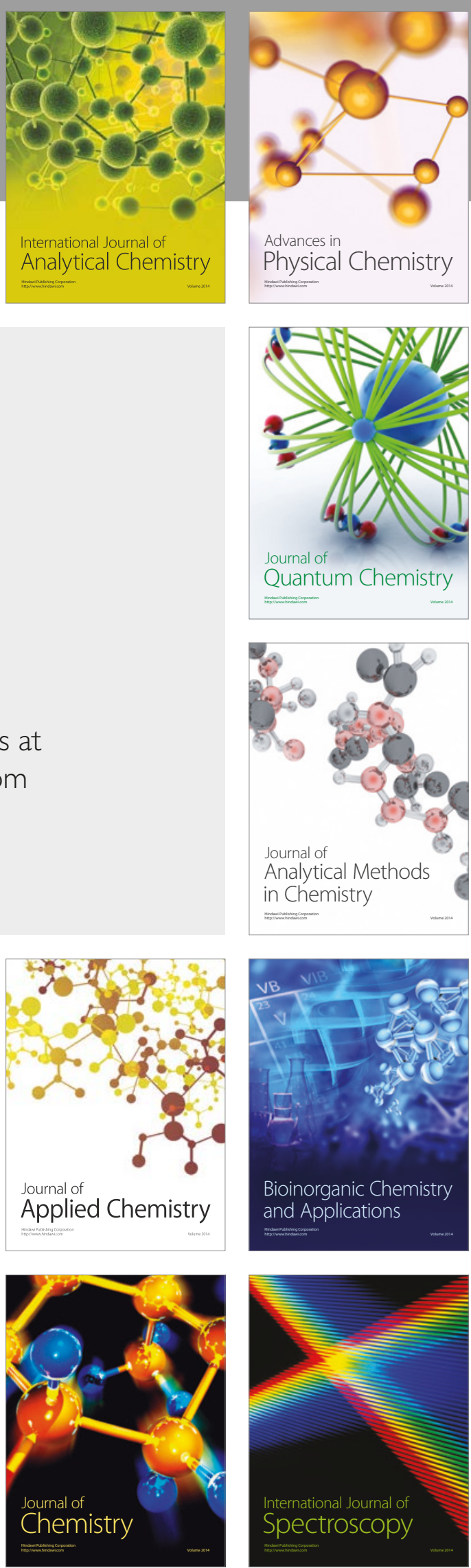